\title{
The Calculation of Coal Rock Fracture Conductivity with Different Arrangements of Proppants
}

\author{
Yuwei Li $\left(\mathbb{D},{ }^{1,2}\right.$ Wannong Meng, ${ }^{1}$ Ray Rui $\left(\mathbb{D},{ }^{3}\right.$ Jinghui Wang, ${ }^{4}$ Dan Jia, ${ }^{1}$ Gang Chen, \\ Shirish Patil, ${ }^{6}$ and Abhijit Dandekar ${ }^{3}$ \\ ${ }^{1}$ Department of Petroleum Engineering, Northeast Petroleum University, Daqing Heilongjiang 163318, China \\ ${ }^{2}$ Petroleum Engineering Research Institute of Dagang Oilfield Co., Tianjin 300280, China \\ ${ }^{3}$ Department of Petroleum Engineering, University of Alaska Fairbanks, Fairbanks AK 99775, USA \\ ${ }^{4}$ Department of Petroleum Engineering, China University of Petroleum, Beijing 102200, China \\ ${ }^{5}$ Department of Mining and Geological Engineering, University of Alaska Fairbanks, Fairbanks, USA \\ ${ }^{6}$ Department of Petroleum Engineering, King Fahd of Petroleum and Mineral, Dhahran, 31261, Saudi Arabia
}

Correspondence should be addressed to Yuwei Li; liyuwei@nepu.edu.cn and Ray Rui; zrui@alaska.edu

Received 17 July 2017; Revised 12 December 2017; Accepted 21 December 2017; Published 26 September 2018

Academic Editor: Julie K. Pearce

Copyright (C) 2018 Yuwei Li et al. This is an open access article distributed under the Creative Commons Attribution License, which permits unrestricted use, distribution, and reproduction in any medium, provided the original work is properly cited.

\begin{abstract}
An accurate evaluation of coal rock fracture conductivity is an important prerequisite for predicting the productivity of CBM wells. Coal rock is soft and fragile, with low elastic modulus and high Poisson ratio. In the process of fracturing flowback, the contact deformation between proppant and fracture wall will affect the fracture conductivity when the proppant is embedded in the coal rock; thus the calculation method of plate fracture conductivity is no longer suitable for the evaluation of coal rock. Based on the contact deformation theory of elastic mechanics, a method for calculating contact deformation of proppant in fracture is proposed. Considering the effect of the deformation and embedded depth of proppant and the tortuosity of pore flow channel between proppant particles on fracture conductivity, a model for calculating fracture conductivity of coal rock fractures under three kinds of proppant arrangement (Model 4-1, Model 3-1, and Model 2-1) is established. Comparison of calculation results of theoretical model and experiments confirmed that the arrangement of proppant in coal rock fracture is closest to Model 3-1, and the influence of mechanical parameters of coal rock and proppant on fracture conductivity is calculated and analyzed by this theoretical model. The study shows that the coal rock fracture conductivity is affected little by Poisson's ratio of coal rock and proppant, which is greatly influenced by the elastic modulus of them, and the effect of particle size of proppant is especially significant.
\end{abstract}

\section{Introduction}

Hydraulic fracturing is the primary means of stimulating CBM wells and has been widely used in exploration of coalbed methane [1-9]. The fractures produced by hydraulic fracturing can communicate with natural fractures in the coal seam [10-12], enhance the connectivity between natural fractures, greatly improve the permeability of coal reservoir [9], and have a very significant effect of increasing production [13, 14]. To study fracture conductivity, the evaluation begins with the prediction of the fracture productivity after conventional fracturing of sandstone and other conventional reservoirs [15-17]. Much [18], Penny [19], and McDaniel [20, 21] have studied the influence of time and temperature on the longterm conductivity of cracks in medium and hard sandstone formations under certain closed stress conditions. Pope [22] and Gong [23] discussed the effect of the fracturing fluid viscosity on the ability to support fractures, and they established a prediction method of fracture permeability. On the basis of mass balance and the pressure-matching method, Rahim [24] and $\mathrm{Gu}[25]$ theoretically analyzed the relationship between fracture conductivity and formation permeability on the one hand and fracture length and production time on the other hand. After coal seam fracturing, it is more likely to have the complicated conditions such as proppant embedded, fractures wall compaction, and coal dust clogging [26-28]. 
Therefore, the research on fracture conductivity in coal seams cannot follow the methods of conventional oil and gas reservoirs.

Researchers have carried out relevant experimental research on fracture conductivity of coal rock, in terms of proppant embedment, crushing and wall compaction, and the damage of fracture fluid residue to fracture conductivity. Gao [29] carried out a long-term diversion experiment of coal rock and tested the conductivity under the condition of closure pressure and proppant embedment. Liu [30] and Zhang [31] simulated the experiments of fracture conductivity when the proppant was embedded in different coal rock. They proved that the fracture conductivity has a strong sensitivity to stress, and the more severe the proppant is embedded in the coal rock, the greater the damage degree of the fracture conductivity of coal rock fracture is. Wang [32] and Zhang [33], respectively, tested the effects of sand concentration, proppant size, proppant type, fracturing fluid residue, and the breakage and embedment of proppant particles on the fracture conductivity. The results show that the reduction of conductivity caused by the embedment is more serious than that of fracturing fluid residue. Zhang [34] considered proppant embedment and natural fracture and other factors, tested the coal rock fracture conductivity under the condition of low sand concentration, and found that single layer sanding can support coal rock fractures under lower closed pressure and obtain ideal fracture conductivity. Zheng [35] and Dong [36] considered the influence of natural fractures and the properties of coal rock on fracture conductivity and carried out experiments on fracture conductivity of coalbed methane wells. It is proved that natural fractures and cleats in the coal plate have a significant influence on fracture conductivity, and it is beneficial to improve fracture conductivity. Shen [37] conducted a thorough study on the variation of fracture conductivity under high closure pressure. They studied the influence of proppant size and breakage rate on the fracture conductivity, but did not consider the influence of proppant embedment. Obviously, the study on the flow conductivity of coal rock fractures is mostly based on experimental analysis, and there is no more perfect theoretical model to evaluate the conductivity of coal rock fractures accurately. This paper has important theoretical and practical value to establish the corresponding theoretical model.

\section{Calculation Model of Fracture Width}

2.1. Calculation of Deformation and Embedment Depth of Proppants. The schematic diagram of proppant 1 and proppant 2 under closure pressure is shown in Figure 1. According to the literature [38] we can see that the two proppant particles contact area is circular, assuming the radius of the circle is $a$, then

$$
\begin{aligned}
a & =\left(\frac{3}{4} P C_{E} \frac{R_{1} R_{2}}{R_{1}+R_{2}}\right)^{1 / 3} \\
C_{E} & =\frac{1-v_{1}^{2}}{E_{1}}+\frac{1-v_{2}^{2}}{E_{2}}
\end{aligned}
$$

where

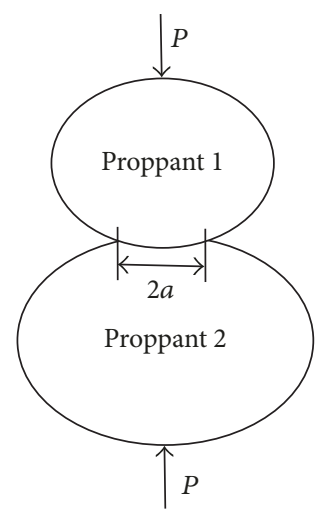

FIGURE 1: Schematic diagram of contact deformation between proppants.

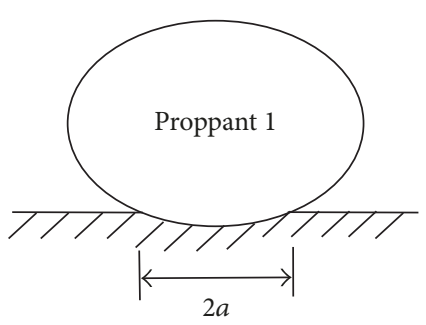

FIGURE 2: Schematic diagram of proppants embedment.

$a$ is the radius of the contact area of the two proppants, $\mathrm{mm}$;

$P$ is the external force acting on the two proppants, $\mathrm{N}$;

$R_{1}$ is the radius of proppant $1, \mathrm{~mm}$;

$R_{2}$ is the radius of proppant 2, mm;

$\gamma_{1}$ is the Poisson ratio of proppant 1 , dimensionless;

$\gamma_{2}$ is the Poisson ratio of proppant 2, dimensionless;

$E_{1}$ is the elastic modulus of proppant $1, \mathrm{MPa}$;

$E_{2}$ is the elastic modulus of proppant 2, MPa.

The theoretical relationship between the two proppants is verified by the following relationship [39]:

$$
\alpha^{\prime}=\frac{(3 / 4) P C_{E}}{\left((3 / 4) P C_{E}\left(R_{1} R_{2} /\left(R_{1}+R_{2}\right)\right)\right)^{1 / 3}}
$$

When $R_{2}$ approaches infinity, proppant 2 can be approximated as the wall of coal rock fractures, as shown in Figure 2, and (3) can be simplified as follows:

$$
\alpha^{\prime}=\frac{2\left((3 / 8) P C_{E} D_{1}\right)^{2 / 3}}{D_{1}}
$$

where $D_{1}$ is the diameter of proppant $1, \mathrm{~mm}$.

The value of $\alpha^{\prime}$ is affected by two factors: the deformation and embedment of the proppants. When the elastic modulus of coal rock wall tends to infinity, the proppants will not be embedded, and the value of $\alpha^{\prime}$ will only affected by the 
deformation of proppants. Then the proppant deformation $\beta$ obtained from (4) can simplified as

$$
\beta=\frac{2\left((3 / 8) P D_{1}\left(\left(1-v_{1}^{2}\right) / E_{1}\right)\right)^{2 / 3}}{D_{1}}
$$

Combining (4) and (5), the embedment depth can be obtained:

$$
\begin{aligned}
h & =\frac{2\left((3 / 8) P D_{1}\right)^{2 / 3}}{D_{1}}\left[\left(\frac{1-v_{1}^{2}}{E_{1}}+\frac{1-v_{2}^{2}}{E_{2}}\right)\right. \\
& \left.-\left(\frac{1-v_{1}^{2}}{E_{1}}\right)^{2 / 3}\right]
\end{aligned}
$$

According to Hooke's law, when the proppant interacts with the wall of coal rock, it will cause the compacted deformation. It is assumed that the effective thickness of coal seam is $D_{2}$, then the deformation $\Delta D_{2}$ in closure pressure can be expressed as

$$
\Delta D_{2}=D_{2} \frac{P}{E_{2}}
$$

where

$D_{2}$ is the effective thickness of coal seam, mm;

$P$ is the closure pressure, MPa.

The deformation is caused by the embedment, so the thickness of coal rock without embedding is still initial value. Combining $(4) \sim(7)$, the following equations can be obtained:

$$
\begin{aligned}
\alpha^{\prime} & =\frac{2\left((3 / 8) P C_{E} D_{1}\right)^{2 / 3}}{D_{1}}+D_{2} \frac{P}{E_{2}} \\
h & =\frac{2\left((3 / 8) P D_{1}\right)^{2 / 3}}{D_{1}}\left[\left(\frac{1-v_{1}^{2}}{E_{1}}+\frac{1-v_{2}^{2}}{E_{2}}\right)\right. \\
& \left.-\left(\frac{1-v_{1}^{2}}{E_{1}}\right)^{2 / 3}\right]+D_{2} \frac{P}{E_{2}} .
\end{aligned}
$$

2.2. Calculation of Fracture Width. Assuming that, under the closure pressure, the number of proppant layers between two walls of coal rock fracture is $n$, and the distance between the two proppant layers is equal, expressed in $h_{\mathrm{q}}$ :

$$
W=(n-1) h_{q}+D_{1}-2(\beta-h)
$$

That is,

$$
\begin{aligned}
W & =(n-1) h_{q}+D_{1} \\
& -2\left(\frac{2\left((3 / 8) P D_{1}\left(\left(1-v_{1}^{2}\right) / E_{1}\right)\right)^{2 / 3}}{D_{1}}\right.
\end{aligned}
$$

$$
\begin{aligned}
& -\frac{2\left((3 / 8) P D_{1}\right)^{2 / 3}}{D_{1}}\left[\left(\frac{1-v_{1}^{2}}{E_{1}}+\frac{1-v_{2}^{2}}{E_{2}}\right)\right. \\
& \left.\left.-\left(\frac{1-v_{1}^{2}}{E_{1}}\right)^{2 / 3}\right]\right)
\end{aligned}
$$

\section{Calculation Model of Fracture Permeability}

The total number of proppants embedded in the seam is denoted by $N$, and $N_{1}$ is the number of proppants adjacent to the wall of fracture. $N^{\prime}$ denotes the number of internal channels in the seam, and $n^{\prime}$ the number of channels of coal walls.

$N$ represents the total number of proppant laying in the coal rock fracture, and $N_{1}$ represents the number of proppant adjacent to the double wall of the seam. Then the total volume of embedded proppant $V$ and other parameters can be expressed by the following equations:

$$
\begin{aligned}
V & =N_{1} \times V^{\prime}=N_{1} \times \pi h^{2}\left(R-\frac{h}{3}\right) \\
N & =\left[n\left(\frac{H}{2 R}\right)_{\mathrm{int}}-A\right]\left(\frac{L}{2 R}\right)_{\mathrm{int}} \\
N_{1} & =\left(\frac{H}{2 R}\right)_{\mathrm{int}}\left(\frac{L}{2 R}\right)_{\mathrm{int}}+\left[\left(\frac{H}{2 R}\right)_{\mathrm{int}}-B\right]\left(\frac{L}{2 R}\right)_{\mathrm{int}}
\end{aligned}
$$

where

$n$ is the layers for proppants in coal rock;

$H$ and $L$ are respectively the height and length of coal rock fracture, $\mathrm{m}$.

A is constant; when $n=3 m-2, \mathrm{~A}=2 m-2$; when $n=3 m-1$, $\mathrm{A}=2 m-1$; and when $n=3 m, \mathrm{~A}=2 m$.

$\mathrm{B}$ is constant; when $n=3 m-2, \mathrm{~B}=0$; when $n=3 m-1$ or $n=3 m, \mathrm{~B}=1$.

Combining the definition of width and porosity of fractures [39], the depth of embedment $h$ and the porosity of fracture $\varphi$ can be obtained:

$$
\varphi=\frac{L H W-\left((4 / 3) \pi R^{3} N-V\right)}{L H W}
$$

$R_{1}$ and $R_{2}$ are, respectively, the effective radii of the flow channel on the wall and of the internal flow channel of coal rock:

$$
\begin{aligned}
& r_{1}=\sqrt{\frac{L H(2 R-2 \beta+2 h)-N_{1}\left(2 \pi R^{3} / 3\right)+V}{n^{\prime} \pi L}} \\
& r_{2}=\sqrt{\frac{L H(n-1) h-\left(N\left(4 \pi R^{3} / 3\right)-N_{1}\left(2 \pi R^{3} / 3\right)\right)}{n^{\prime} \pi L}}
\end{aligned}
$$




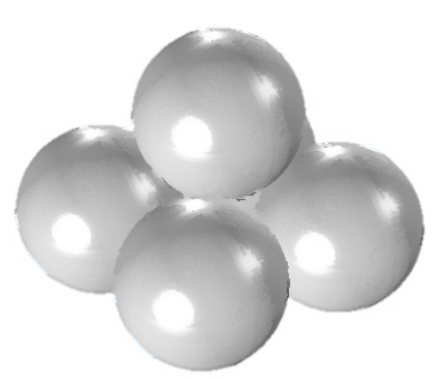

(a) Model 4-1

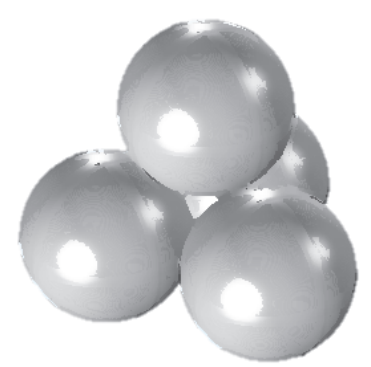

(b) Model 3-1

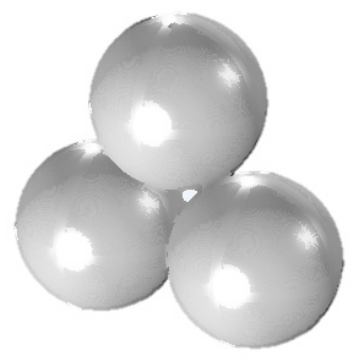

(c) Model 2-1

FIGURE 3: Schematic diagram of 3 kinds of proppant arrangements.

The effective radius of flow channels and the tortuosity of coal rock fractures can be, respectively, expressed as

$$
\begin{aligned}
r & =\frac{2}{n+1} r_{1}+\frac{n-1}{n+1} r_{2} \\
\tau & =\frac{1}{\varphi^{\kappa}}
\end{aligned}
$$

where $\kappa$ is a constant with a value of 0.489 .

The permeability of coal rock with embedment is

$$
\begin{aligned}
K & =\frac{\varphi r^{2}}{8 \tau^{2}} \times 10^{12} \\
& =\frac{\left[L H W-\left((4 / 3) \pi R^{3} N-V\right)\right]}{8 \tau^{2} L H W} r^{2} \times 10^{12}
\end{aligned}
$$

\section{Calculation Model of Fracture Conductivity}

4.1. Stress Analysis of Proppants under Different Arrangements. In this paper, a model for calculating the fracture conductivity of coal rock under 3 kinds of arrangement modes (Model 41, Model 3-1, and Model 2-1) are established. The schematic diagram is shown in Figure 3.

In the different arrangements of proppant, the five, four, and three proppants are, respectively, taken as the study object. The center line constitutes a cube. The upper and lower proppants deform under the closure pressure $P$, while there is no closure pressure between the same layers. The simplified diagram under different arrangement is shown in Figure 4.

4.2. Calculation of the Fracture Conductivity. According to the space geometry theory, the equation for calculating the distance between two deformed proppants can obtained by Figure 4(a):

$$
h_{q}=\sqrt{(D-\alpha)^{2}-\frac{1}{2} D^{2}}
$$

As shown in Figure 5, in Model 4-1, a stress unit consists of four proppants in the same layer. Assume that every proppant has the same diameter, that is, $R_{1}=R_{2}=D / 2$.
The proppant is arranged closely, and the center line forms a square whose diameter is $D$. The area of the square $s$ is

$$
s=D^{2}
$$

The external force $P$ and the closure pressure $p$ satisfy the following relationships:

$$
\begin{aligned}
& P=p_{s}, \\
& p=p_{0}-p_{i}
\end{aligned}
$$

where

$$
\begin{aligned}
& p_{0} \text { is the overburden pressure, } \mathrm{MPa} \text {; } \\
& p_{\mathrm{i}} \text { is the net pressure, } \mathrm{MPa} \text {; } \\
& D \text { is the diameter of proppant, } \mathrm{m} \text {. }
\end{aligned}
$$

By the definition of fracture diversion capacity, the fracture conductivity of coal rock $K W$ is

$$
K W=\frac{\left[L H W-\left((4 / 3) \pi R^{3} N-V\right)\right]}{8 \tau^{2} L H} r^{2} \times 10^{14}
$$

With (8) (11) and (20) (23) substituted into the above formula, a model for calculating the fracture conductivity of coal rock considering the factors of proppant embedment and deformation in Model 4-1 is given. Similarly, the fracture conductivity of Model 3-1 and Model 2-1 can be obtained, respectively.

4.3. Model Application and Validation. First, the theoretical model is used to calculate the theoretical value of the fracture conductivity of coal rock under the same conditions as the experimental parameters in the laboratory. The number of proppants layer $n$ can be obtained from the following equation:

$$
n=\frac{\sqrt{6}}{2 D}\left(\frac{m}{\rho S}-D\right)+1
$$

where 


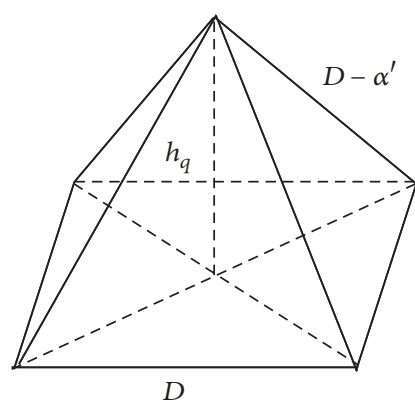

(a) Model 4-1

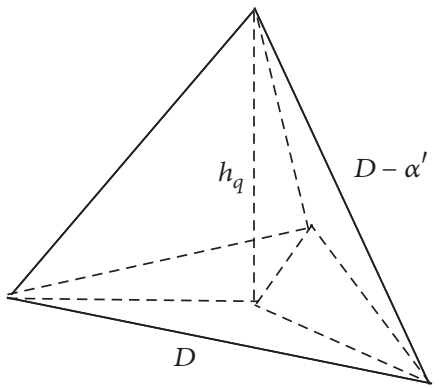

(b) Model 3-1

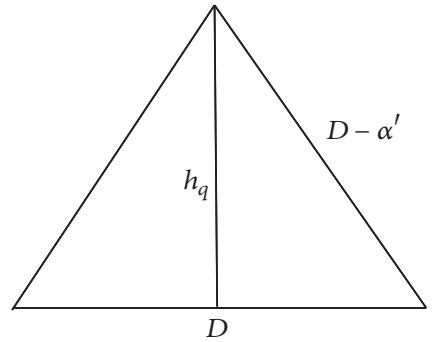

(c) Model 2-1

FIGURE 4: Simplified diagram under three arrangement modes.

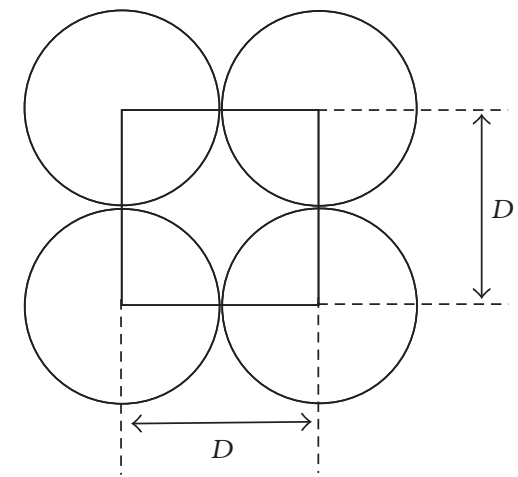

FIGURE 5: Schematic diagram of stress unit in the same layer.

$m$ is the mass of proppants, $\mathrm{g}$;

$\rho$ is the apparent density of proppant, $\mathrm{g} / \mathrm{cm}^{3}$;

$S$ is the area of facture wall, $\mathrm{cm}^{2}$.

$D$ is the diameter of proppant, $\mathrm{cm}$.

The proppant in this paper is taken from Daqing oilfield, the density and concentration are, respectively, $1.692 \mathrm{~g} / \mathrm{cm}^{3}$ and $10 \mathrm{~kg} / \mathrm{m}^{2}$, the total length of diversion chamber is $17.7 \mathrm{~cm}$, and its end is semicircle with diameter $3.81 \mathrm{~cm}$. The equivalent particle size of $20 \sim 40$ mesh is calculated to be $0.6106 \times$ $10^{-4} \mathrm{~m}$ by using geometric weighted average method, and the corresponding sand layer is calculated as 12 layers when the concentration is $10 \mathrm{~kg} / \mathrm{m}^{2}$.

Parameters such as elastic modulus and Poisson's ratio of coal and proppant are provided by Daqing oilfield, and the experimental parameters are shown in Table 1.

After the test of coal rock fracture conductivity, the coal plate is shown in Figure 6. It can be clearly seen that the coal plate and proppant did not rupture, indicating that the experiment can adequately reflect the variation of fracture conductivity.

The average value of fracture conductivity of each pressure test point in the same period is taken as the test result of the fracture conductivity of coal rock; the theoretical results of fracture conductivity of coal rock under different pressures and the comparison curves with experimental results are shown in Table 2 and Figure 7(a). In order to ensure the feasibility of the theoretical model, the data of Meng [40] is also used to prove the accuracy of the theoretical model in this paper. It should be noted that Meng's data lack mechanical parameters of coal rock and proppants, so we assume that the mechanical parameters of coal rock and proppant are the same as those of this paper, and the comparison curves are shown Figure 7(b).

The two groups of comparison curves of fracture conductivity between theoretical and experimental results in Figures $7(a)$ and 7 (b) both show that the calculated results have the same trend as experimental data; thus the accuracy of the theoretical model is verified. With the increase of closure pressure, the pore volume of fractures decreases, leading to a significant decrease in the conductivity of coal rock. For Meng's experiments, the arrangement of proppants meets both Model 3-1 and Model 4-1. But it is obvious that Model 4-1 is more consistent with the experimental results, and if the next step of sensitivity analysis based on the experimental data of Meng, Model 4-1 should be considered. However, it can be seen from the comparison curves that, in the actual fracturing process in this paper, the arrangement of proppants in coal rock fractures meets Model 3-1. Therefore, Model 3-1 is chosen as the theoretical model in this paper, and the influence of various factors on fracture conductivity of coal rock under the condition of Model 3-1 is discussed.

\section{Sensitivity Analysis}

Through the previous model verification, the theoretical model of this paper is found to be more consistent with Model $3-1$, so the sensitivity analysis of this paper has been based on Model 3-1, and the change of fracture conductivity with the various factors is also based on the Model 3-1.

5.1. Influence of Poisson's Ratio of Coal Rock. The theoretical values of fracture conductivity of coal rock are calculated under the condition that Table 1 and other parameters are kept unchanged. The closure pressure is $20 \mathrm{MPa}$ and the Poisson's ratio of coal rock ranges from 0.15 to 0.35 , the results are shown in Table 3 , and the curve of fracture conductivity and Poisson's ratio of coal rock is shown in Figure 8.

It can be seen from the diagram that the influence of coal rock Poisson's ratio on fracture conductivity is very small. With the increase of coal rock Poisson's ratio, the fracture 

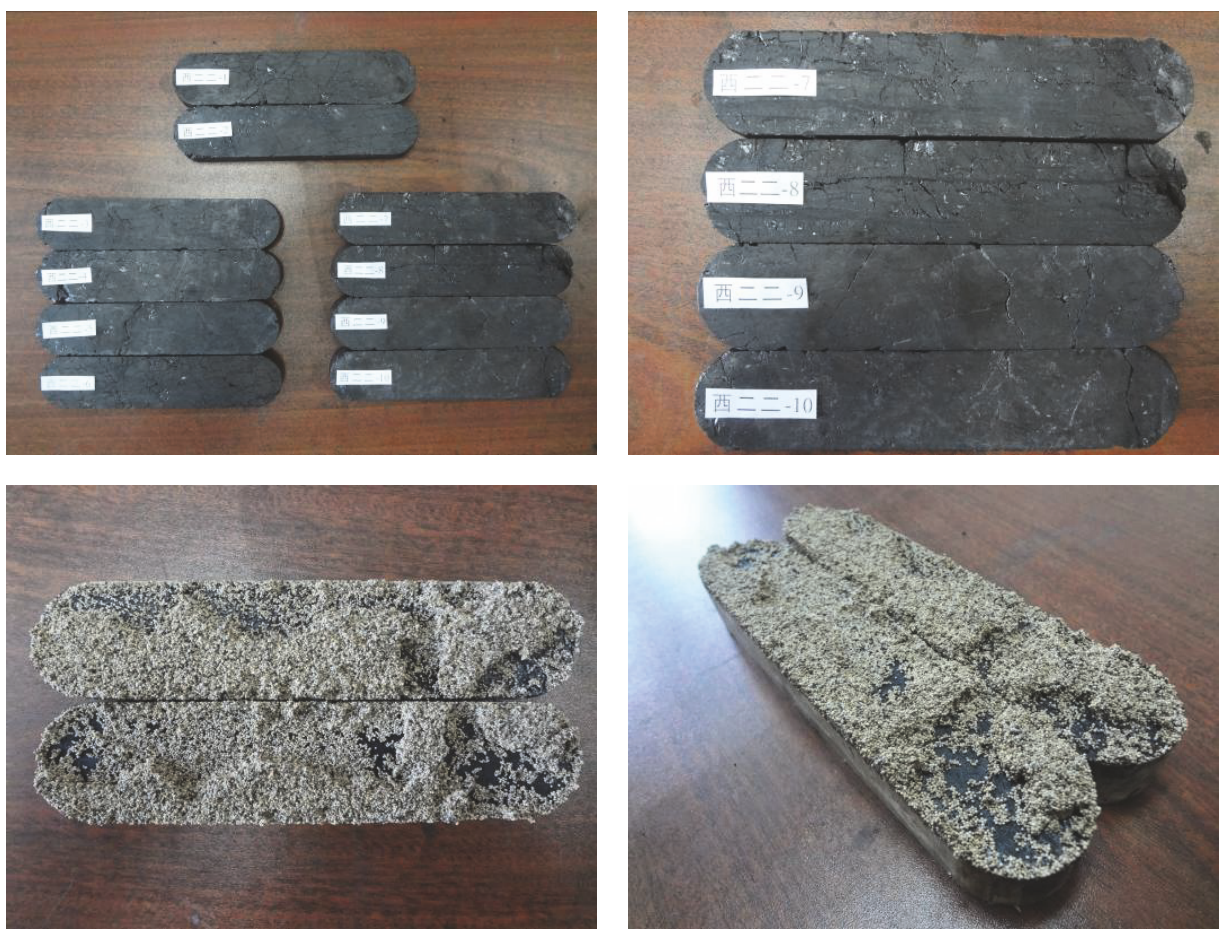

FIGURE 6: Coal plate shape before and after fracture conductivity test.

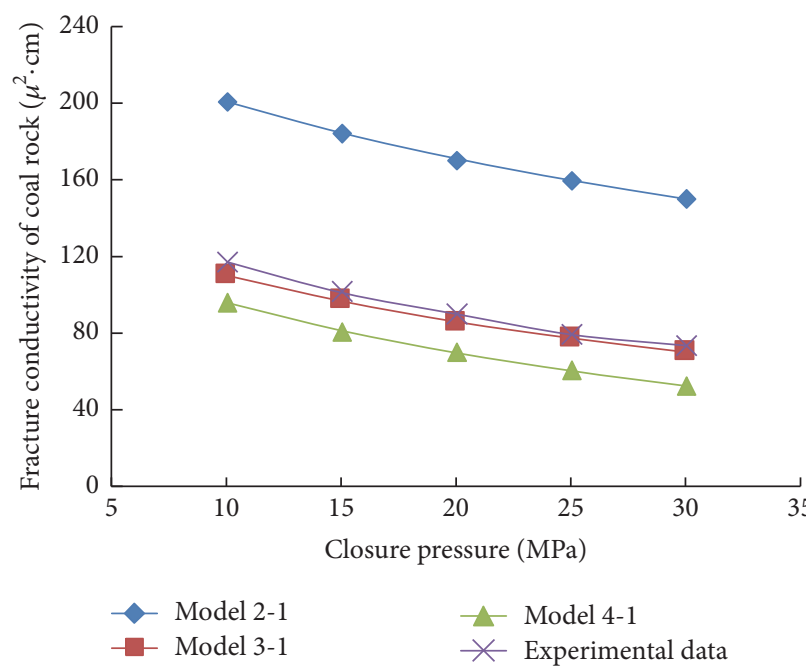

(a) Comparison curves of fracture conductivity between theoretical and experimental results

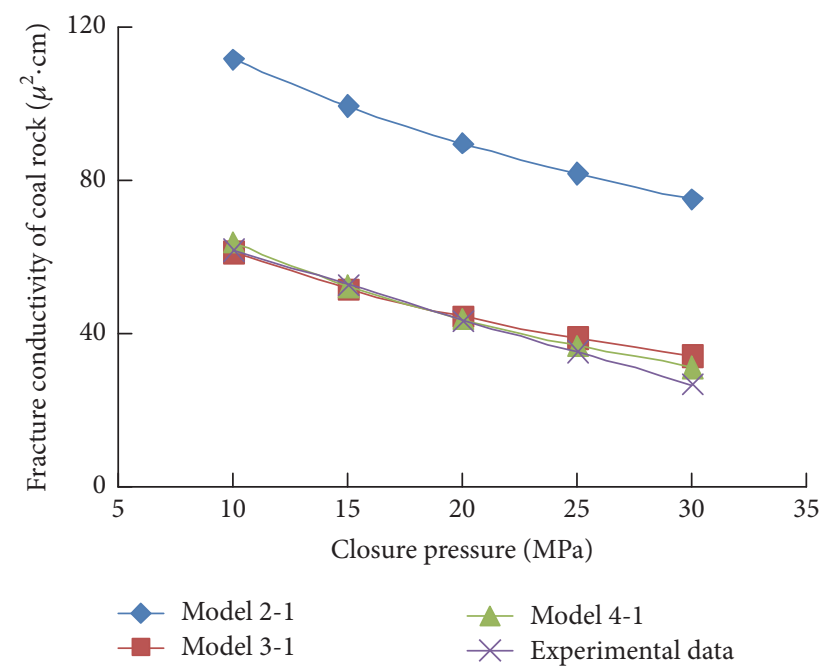

(b) Comparison curves of fracture conductivity between theoretical and experimental results (experimental data of Meng et al. 2014)

FIGURE 7

TABLE 1: Experimental parameters of coal rock and proppant.

\begin{tabular}{|c|c|c|c|c|c|c|c|c|}
\hline $\begin{array}{l}\text { Concentration } \\
\text { of proppant } \\
\left(\mathrm{kg} \cdot \mathrm{m}^{-2}\right)\end{array}$ & $\begin{array}{l}\text { Diameter of } \\
\text { proppant }(\mathrm{m})\end{array}$ & $\begin{array}{c}\text { Closure } \\
\text { pressure }(\mathrm{MPa})\end{array}$ & $\begin{array}{c}\text { Elastic } \\
\text { modulus of } \\
\text { proppant } \\
(\mathrm{GPa})\end{array}$ & $\begin{array}{c}\text { Poisson's ratio } \\
\text { of proppant }\end{array}$ & $\begin{array}{c}\text { Elastic } \\
\text { modulus of } \\
\text { coal rock } \\
(\mathrm{GPa})\end{array}$ & $\begin{array}{l}\text { Poisson's ratio } \\
\text { of coal rock }\end{array}$ & $\begin{array}{l}\text { Height of } \\
\text { fracture } \\
\text { (m) }\end{array}$ & $\begin{array}{l}\text { Length of } \\
\text { fracture } \\
\quad(\mathrm{m})\end{array}$ \\
\hline 10 & $6.106 \times 10^{-4}$ & $10 \sim 30$ & 20.338 & 0.142 & 1.205 & 0.221 & 0.0381 & 0.127 \\
\hline
\end{tabular}


TABLE 2: Comparison of experimental and theoretical results of coal rock fracture conductivity.

\begin{tabular}{|c|c|c|c|c|c|}
\hline & $10 \mathrm{MPa}$ & $15 \mathrm{MPa}$ & $20 \mathrm{MPa}$ & $25 \mathrm{MPa}$ & $30 \mathrm{MPa}$ \\
\hline Model 2-1 & 200.185 & 183.888 & 170.467 & 159.175 & 149.466 \\
\hline Model 3-1 & 110.027 & 96.936 & 85.905 & 77.268 & 69.955 \\
\hline Model 4-1 & 95.554 & 81.275 & 69.917 & 60.770 & 53.067 \\
\hline Experimental data & 117.641 & 101.434 & 90.317 & 79.398 & 73.697 \\
\hline
\end{tabular}

TABLE 3: Fracture conductivity under different Poisson's ratio of coal rock.

\begin{tabular}{lccccc}
\hline Poisson's ratio of coal rock & 0.15 & 0.20 & 0.25 & 0.30 & 0.35 \\
\hline Fracture conductivity of coal rock $/\left(\mu \mathrm{m}^{2} \cdot \mathrm{cm}\right)$ & 86.090 & 86.164 & 86.260 & 86.379 & 86.522 \\
\hline
\end{tabular}

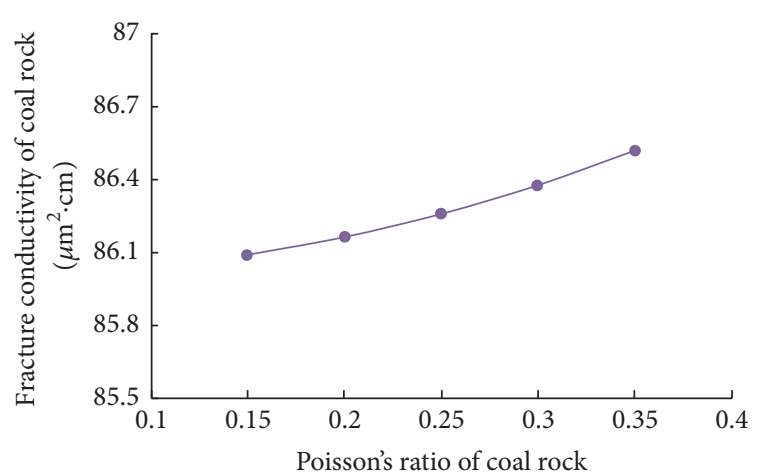

FIgURE 8: Relationship curve of fracture conductivity and Poisson's ratio of coal rock.

conductivity increases slightly, but the increase rate is less than $1 \%$. Therefore, in the field of construction error within the allowable range, the impact is negligible.

5.2. Influence of Elastic Modulus of Coal Rock. In order to study the influence of elastic modulus of coal rock on fracture conductivity, the theoretical values of fracture conductivity of coal rock complex fracturing system under the condition that the other calculation parameters of Table 1 remain unchanged, the closure pressure is $20 \mathrm{MPa}$, and the coal rock elastic modulus changes in the range of $2 \mathrm{GPa} \sim 6 \mathrm{GPa}$ are calculated, as shown in Table 4.

The relationship between fracture conductivity and elastic modulus of coal rock is obtained, as shown in Figure 9. It can be seen that, with the increase of the elastic modulus of coal rock, the fracture conductivity is gradually increasing, but the increase rate is gradually slowed down. When the coal rock elastic modulus is less than $3 \mathrm{GPa}$, the coal rock fracture conductivity increases greatly. When the coal rock elastic modulus is greater than $3 \mathrm{GPa}$, the coal rock fracture conductivity increased to a lesser extent. This is mainly due to the fact that the greater the elastic modulus of coal rock is, the shallower the proppant embedment depth is, the greater the fracture porosity is, and thus the higher the fracture conductivity is.

5.3. Influence of Elastic Modulus and Poisson's Ratio of Proppant. Similarly, keeping the other calculated parameters in Table 1 unchanged, the theoretical values are, respectively, calculated at $20 \mathrm{MPa}$ when proppant Poisson's ratio ranges

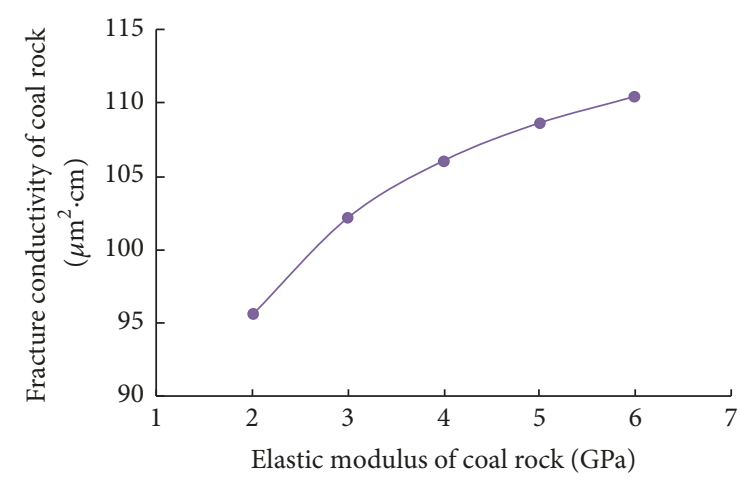

FIGURE 9: Relationship curve of fracture conductivity and elastic modulus of coal rock.

from 0.1 to 0.3 and proppant elastic modulus ranges from $10 \mathrm{GPa}$ to $35 \mathrm{GPa}$.

As can be seen from Figure 10, Poisson's ratio of proppant has little influence on coal rock fracture conductivity, and the trend of Poisson's ratio of proppant has the same influence as that of coal rock on conductivity. With the increase of proppant Poisson's ratio, the fracture conductivity increases slightly, but the increase is less than $2 \%$. As shown in Figure 11, with the increase of proppant elastic modulus, fracture conductivity increased, but the rate of increase slowed down gradually. This is mainly due to the fact that the greater the elastic modulus of proppant is, the more difficult it is for proppant to deform, the larger the pore space between proppant is, and thus the higher the fracture conductivity is.

5.4. Influence of Proppant Size. The theoretical values are calculated at $20 \mathrm{MPa}$ when the other calculated parameters in Table 1 are unchanged and the proppant size changes from $0.3 \mathrm{~mm}$ to $0.7 \mathrm{~mm}$.

It can be seen from Figure 12 that, with the increase of the particle size of proppant, the fracture conductivity is gradually increased and the variation range is increasing. When the proppant diameter is less than $0.5 \mathrm{~mm}$, the coal rock fracture conductivity increased to a lesser extent. When the proppant diameter is greater than $0.5 \mathrm{~mm}$, the conductivity increases greatly, which is mainly due to the fact that, with the increase of proppant size, the pore space between particles increases, and the fluid is easier to pass through. So that the fracture conductivity also increases. 
TABLE 4: Fracture conductivity under different elastic modulus of coal rock.

\begin{tabular}{lcccc}
\hline Elastic modulus of coal rock / GPa & 2 & 3 & 4 & 5 \\
\hline Fracture conductivity of coal rock $/\left(\mu \mathrm{m}^{2} \cdot \mathrm{cm}\right)$ & 95.628 & 102.207 & 106.070 & 108.614 \\
\hline
\end{tabular}

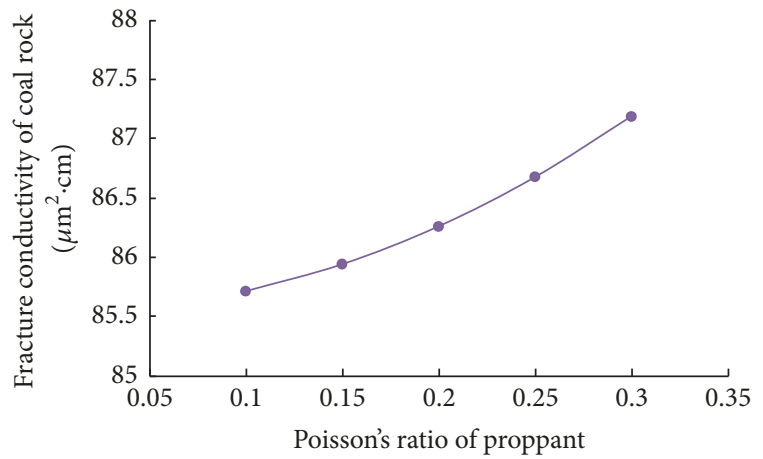

Figure 10: Relationship curve of fracture conductivity and Poisson's ratio of proppant.

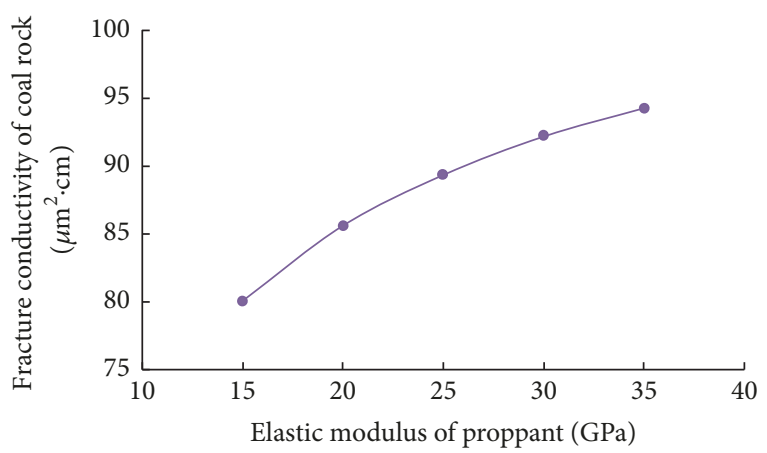

FIGURE 11: Relationship curve of fracture conductivity and elastic modulus of coal rock.

5.5. Discussion. The accurate calculation of coal rock conductivity can provide important theoretical basis for CBM wells fracturing scheme design and production prediction after fracturing. Coal rock is soft and brittle with the characteristics of low modulus and high Poisson's ratio; coal powder is easy to fall off and plug fractures in the process of fracturing. And under the closure pressure, proppant deformation and embedment are prone to occur, which leads to significant changes in fracture width and porosity and changes in fracture conductivity. On the other hand, different arrangements of proppants have a significant effect on the fracture width and porosity under the closure pressure, thus affecting and changing the conductivity of fractures. This paper properly considered the special mechanical characteristics of coal rock and the influence of proppants arrangements and embedments. The paper studied the fracture conductivity of coal rock both from theoretical and experimental aspects. In the past, the research on coal rock fracture conductivity basically used the method of experimental evaluation, Gao [29], Liu [41], and Zhang [31] et al. analyzed the effects of closure pressure and proppants embedment on fracture conductivity experimentally. Wang [32], Zhang [33], and

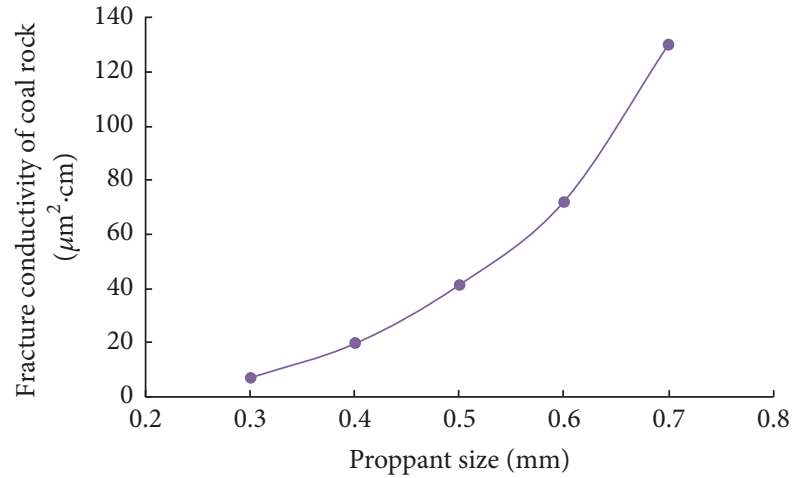

FIGURE 12: Relationship curve of fracture conductivity and proppant diameter.

Shen [37] et al. mainly studied the influence of proppants concentration and proppants size on the fracture conductivity. In this paper, not only is the influence of fracture closure pressure and proppants embedment studied, but also the calculation model describing the conductivity of coal rock under different arrangements of proppants is established theoretically. The research work is more theoretical and innovative. According to the calculation results of the model, the main factors affecting the conductivity of coal rock fractures are the elastic modulus of coal and proppants and the particle size of proppant. Relative to the unchangeable mechanical parameters such as elastic modulus and Poisson's ratio of coal, the effective means to improve the fracture conductivity is to increase the elastic modulus and particle size of proppants. That is to say, if conditions permit, large size and high strength proppants should be used as much as possible so as to effectively increase fracture conductivity and obtain higher CBM well productivity. However, the increase of proppant size and strength may also adversely affect the proppant transport and migration in the fracturing fluid during fracturing, which also needs to be fully considered in fracturing design. In addition, the calculation model of coal rock fracture conductivity with different arrangements of proppants did not consider the effect of the pulverized coal and proppant breakage on the permeability and conductivity of fractures, which is still needs to be supplemented and improved. Through the follow-up study and solving this difficult problem, the model assumptions can be more in line with the actual situation, so that the research results have more practical application value.

\section{Conclusions}

(1) The study in laboratory shows that the proppant arrangement in coal rock fractures can be Model 3-1 or Model 4-1 when the proppant is packed tightly, but, in this paper, is more close to Model 3-1. 
(2) The fracture conductivity of coal rock is less affected by Poisson's ratio of coal rock and proppant, but obviously affected by elastic modulus of coal rock and proppant. With the increase of elastic modulus, the fracture conductivity increases.

(3) Proppant size has the most significant influence on fracture conductivity of coal rock. With the increase of particle size, the fracture conductivity increases significantly.

\section{Conflicts of Interest}

The authors declare that there are no conflicts of interest regarding the publication of this article.

\section{Acknowledgments}

The research was supported by Natural Science for Youth Foundation of China (no. 51504068), University Nursing Program for Young Scholars with Creative Talents in Heilongjiang Province (UNPYSCT-2016124), and Northeast Petroleum University Scientific Research Start Funds Subsidization Project and National Natural Science Foundation of China (no. 51490650).

\section{References}

[1] J. H. Zhao, "Current status of coal-bed gas exploration in China and suggestions on its development," Sino-Global Energy, vol. 13, no. 4, pp. 30-34, 2008.

[2] S.Z. Li and Y. J. Qu, "Coalbed methane and shale gas exploration and development in the United States and the suggestions for China," China Mining Magazine, vol. 12, pp. 17-21, 2010.

[3] Y. Li, D. Jia, M. Wang et al., "Hydraulic fracturing model featuring initiation beyond the wellbore wall for directional well in coal bed," Journal of Geophysics and Engineering, vol. 13, no. 4, pp. 536-548, 2016.

[4] Y.-W. Li, J. Zhang, and Y. Liu, "Effects of loading direction on failure load test results for Brazilian tests on coal rock," Rock Mechanics and Rock Engineering, vol. 49, no. 6, pp. 2173-2180, 2016.

[5] Y. Li, D. Jia, J. Liu, C. Fu, and C. Ai, "The calculation method based on the equivalent continuum for the fracture initiation pressure of fracturing of coalbed methane well," Journal of Petroleum Science and Engineering, vol. 146, pp. 909-920, 2016.

[6] Y. D. Zhang, S. H. Tang, and S. X. Zhang, "Thinking of coal bed methane development in China according to abroad countries development experiments," China Mining Magazine, vol. 22, pp. 4-6, 2013.

[7] Z. L. Wang, Research on underground hydraulic fracturing technology in low permeability coal seam [Ph.D. Dissertation], China University of Mining \& Technology, Beijing, China, 2015.

[8] X. Z. Li, he mechanism and technology of permeability enhancements in coal seam based on high pressure pulsating hydraulic fracturing [Ph.D. Dissertation], China University of Mining \& Technology, Beijing, China, 2013.

[9] Z. G. Yuan, Research on crack propagation of hydraulic fracturing for coal-rock mass and its influence on gas migration [Ph.D. Dissertation], Chongqing University, Chongqing, China, 2014.

[10] S. Huang, D. Liu, Y. Yao, Q. Gan, Y. Cai, and L. Xu, "Natural fractures initiation and fracture type prediction in coal reservoir under different in-situ stresses during hydraulic fracturing,"
Journal of Natural Gas Science and Engineering, vol. 43, pp. 6980, 2017.

[11] T. Wang, W. Hu, D. Elsworth et al., "The effect of natural fractures on hydraulic fracturing propagation in coal seams," Journal of Petroleum Science and Engineering, vol. 150, pp. 180-190, 2017.

[12] S. Liu, S. Sang, Z. Pan et al., "Study of characteristics and formation stages of macroscopic natural fractures in coal seam \#3 for CBM development in the east Qinnan block, Southern Quishui Basin, China," Journal of Natural Gas Science and Engineering, vol. 34, pp. 1321-1332, 2016.

[13] Y. Qin, Y. Li, J. Bai, W. Yu, and H. Cheng, "Technologies in the CBM drainage and production of wells in the southern Qinshui Basin with high-rank coal beds," Natural Gas Industry, vol. 31, no. 11, pp. 22-25, 2011.

[14] T. T. Luo, Coal rock characteristics and fracturing methords for Qinshui reservoir [Ph.D. Dissertation], Chengdu University of Technology, Chengdu, China, 2010.

[15] X. Yan, Z. Huang, J. Yao, W. Song, Y. Li, and L. Gong, “Theoretical analysis of fracture conductivity created by the channel fracturing technique," Journal of Natural Gas Science and Engineering, vol. 31, pp. 320-330, 2016.

[16] X. Ma, R. Hao, X. Lai et al., "Field test of volume fracturing for horizontal wells in Sulige tight sandstone gas reservoirs, NW China," Petroleum Exploration and Development, vol. 41, no. 6, pp. 810-816, 2014.

[17] J. Guo, B. Luo, C. Lu, J. Lai, and J. Ren, "Numerical investigation of hydraulic fracture propagation in a layered reservoir using the cohesive zone method," Engineering Fracture Mechanics, vol. 186, pp. 195-207, 2017.

[18] M. G. Much and G. S. Penny, "Long-term performance of proppants under simulated reservoir conditions," in Low Permeability Reservoirs Symposium, Society of Petroleum Engineers, 1987.

[19] G. S. Penny, "An evaluation of the effects of environmental conditions and fracturing fluids upon the long-term conductivity of proppants," in Proceedings of the SPE Annual Technical Conference and Exhibition, Society of Petroleum Engineers, 1987.

[20] B. W. McDaniel, "Conductivity Testing of Proppants at High Temperature and Stress," in Proceedings of the SPE California Regional Meeting, Society of Petroleum Engineers, April 1986.

[21] B. W. McDaniel, "Realistic Fracture Conductivities of Proppants as a Function of Reservoir Temperature," in Proceedings of the Low Permeability Reservoirs Symposium, Society of Petroleum Engineers, 1987.

[22] D. S. Pope, L. K. Leung, J. Gulbis, and V. G. Constien, "Effects of viscous fingering on fracture conductivity," SPE Production and Facilities, vol. 11, no. 4, pp. 230-237, 1996.

[23] M. Gong, S. Lacote, and A. D. Hill, "A New Model of Acid Fracure Conductivity Based on Deformation of Surface Asperities," in Proceedings of the In SPE Formation Damage Control Conference, Society of Petroleum Engineers, 1998.

[24] Z. Rahim, H. Al-Anazi, A. Al-Kanaan, S. Aramco, R. Kayumov, and A. Makmun, "Fracture conductivity calculation using mass balance, modeling, and well performance data in Saudi Arabian deep gas reservoirs," in Proceedings of the International Petroleum Technology Conference 2014 - Innovation and Collaboration: Keys to Affordable Energy, IPTC 2014, pp. 1902-1911, December 2014. 
[25] M. Gu, P. Kulkarni, M. Rafiee, E. Ivarrud, and K. Mohanty, "Understanding the optimum fracture conductivity for naturally fractured shale and tight reservoirs," in Proceedings of the SPE Canadian Unconventional Resources Conference 2014, pp. 986-1003, Society of Petroleum Engineers, October 2014.

[26] Z. Yao, D. Cao, Y. Wei, X. Li, X. Wang, and X. Zhang, "Experimental analysis on the effect of tectonically deformed coal types on fines generation characteristics," Journal of Petroleum Science and Engineering, vol. 146, pp. 350-359, 2016.

[27] M. H. Rahman, M. T. Islam, T. I. Minhaj, M. A. K. Azad, M. M. Hasan, and A. M. R. Haque, "Study of thermal conductivity and mechanical property of insulating firebrick produced by local clay and petroleum coal dust as raw materials," Procedia Engineering, vol. 105, pp. 121-128, 2015.

[28] J. Zhang, M. Li, Z. Liu, and N. Zhou, "Fractal characteristics of crushed particles of coal gangue under compaction," Powder Technology, vol. 305, pp. 12-18, 2017.

[29] K. Li, Y. Gao, Y. Lyu, and M. Wang, "New mathematical models for calculating proppant embedment and fracture conductivity," SPE Journal, vol. 20, no. 3, pp. 496-507, 2015.

[30] Y. Liu, S. A. Zhang, H. N. Shi, L. H. Cao, T. T. Li, and W. $\mathrm{Zhu}$, "Experimental research on flow conductivity of different firmness coal rock embedded by proppant," Oil Drilling \& Production Technology, vol. 35, no. 2, pp. 75-78, 2013.

[31] S. B. Zhang, X. B. Su, and H. Y. Guo, "Controlling the damage of conductivity of hydraulic fractures during the process of drainage in coalbed methane well," Journal of China Coal Society, vol. 39, no. 1, pp. 124-128, 2014.

[32] C. P. Wang, S. C. Zhang, L. Wang, Tang. H. Y., and W. X. Cui, "Experimental evaluation on conductivity of hydraulic fracturing in CBM wells," China Coalbed Methane, vol. 3, no. 1, pp. 1720, 2006.

[33] S. Zhang, S. Mou, J. Zhang, and L. Wang, "Experimental evaluation of long-term conductivity of fracturing in coal beds," Acta Geologica Sinica, vol. 82, no. 10, pp. 1444-1449, 2008.

[34] Y. Zhang, L. Wang, Y.-S. Zou, and T.-K. Guo, "Experimental study on the flow capacity of the fracturing fractures with monolayer proppant in coal beds," Journal of Xian Shiyou University, vol. 27, no. 6, pp. 66-104, 2012.

[35] H. R. Zheng, "Experimental study of conductivity of hydraulic fracture in CBM wells," Journal of Northeast Petroleum University, vol. 37, no. 02, pp. 107-111, 2013.

[36] G. Dong, J. G. Deng, H. Y. Zhu, and Z. R. Chen, "Experimental evaluation on conductivity of hydraulic fracture," in in $C B M$ wells. Science Technology and Engineering, vol. 8, pp. 2049-2052, 2049-2052, 8, 2013.

[37] B. M. Shen, B. Feng, Z. P. Li, W. X. Wang, and G. Liu, "Theoretical derivation of fracture flow capacity under high closure pressure," Journal of Daqing Petroleum Institute, vol. 34, pp. 93-86, 2010.

[38] M. Z. Wang, W. Wang, and J. K. Wu, Elastic Mechanics, Peking University Press, Beijing, China, 2002.

[39] S. L. Yang and J. Z. Wei, Reservoir Physics, Petroleum Industry Press, Beijing, China, 2004.

[40] Y. Meng, Z.-P. Li, and Z.-Z. Guo, "Calculation model of fracture conductivity in coal reservoir and its application," Meitan Xuebao/Journal of the China Coal Society, vol. 39, no. 9, pp. 18521856, 2014.

[41] S. Q. Liu, Geology and engineering cooperative control and prediction for the deliverability of CBM straight wells in southern Qinshui basin [Ph.D. Dissertation], China University of Mining \& Technology, Xuzhou, China, 2013. 

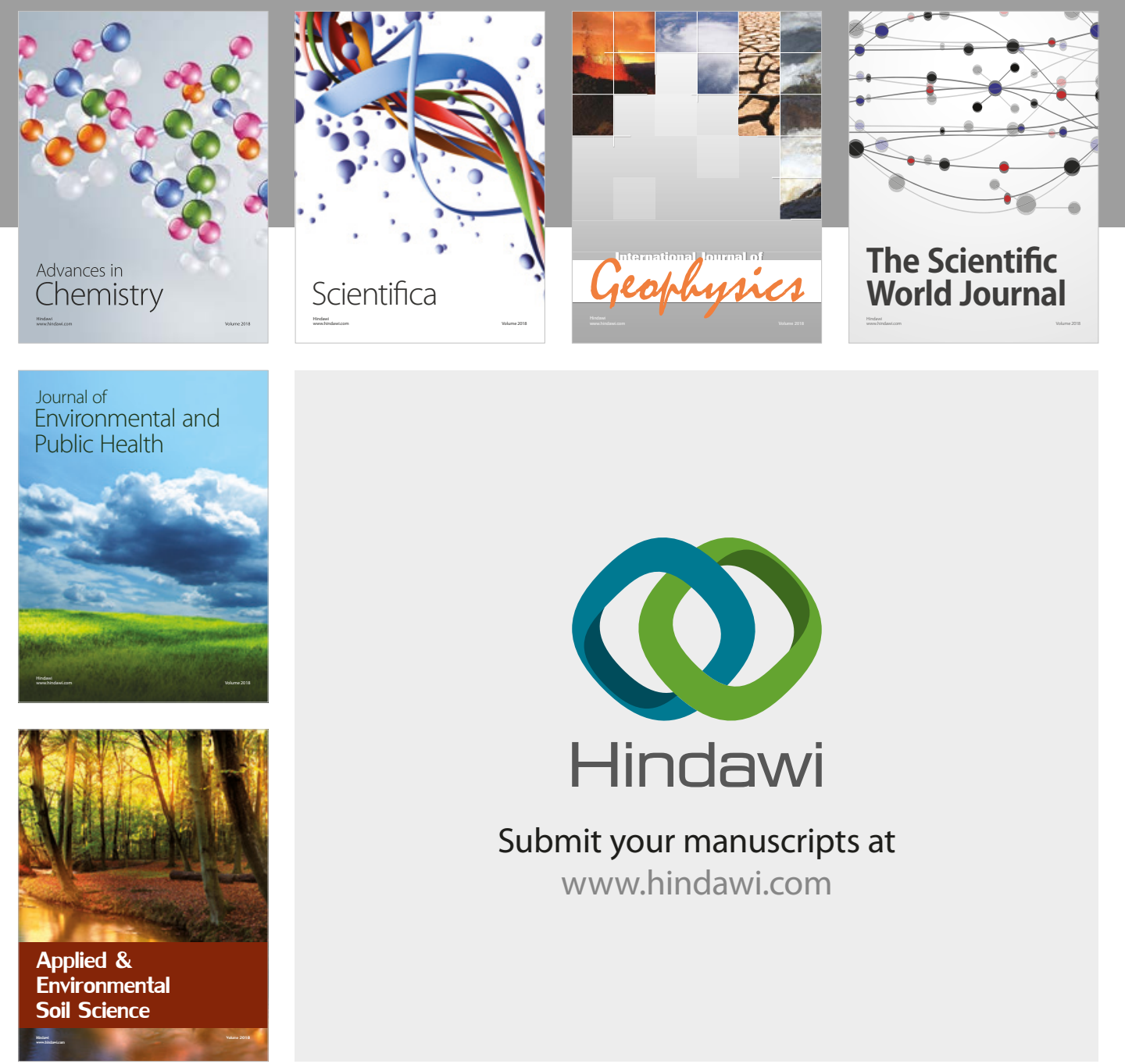

The Scientific

\section{World Journal}
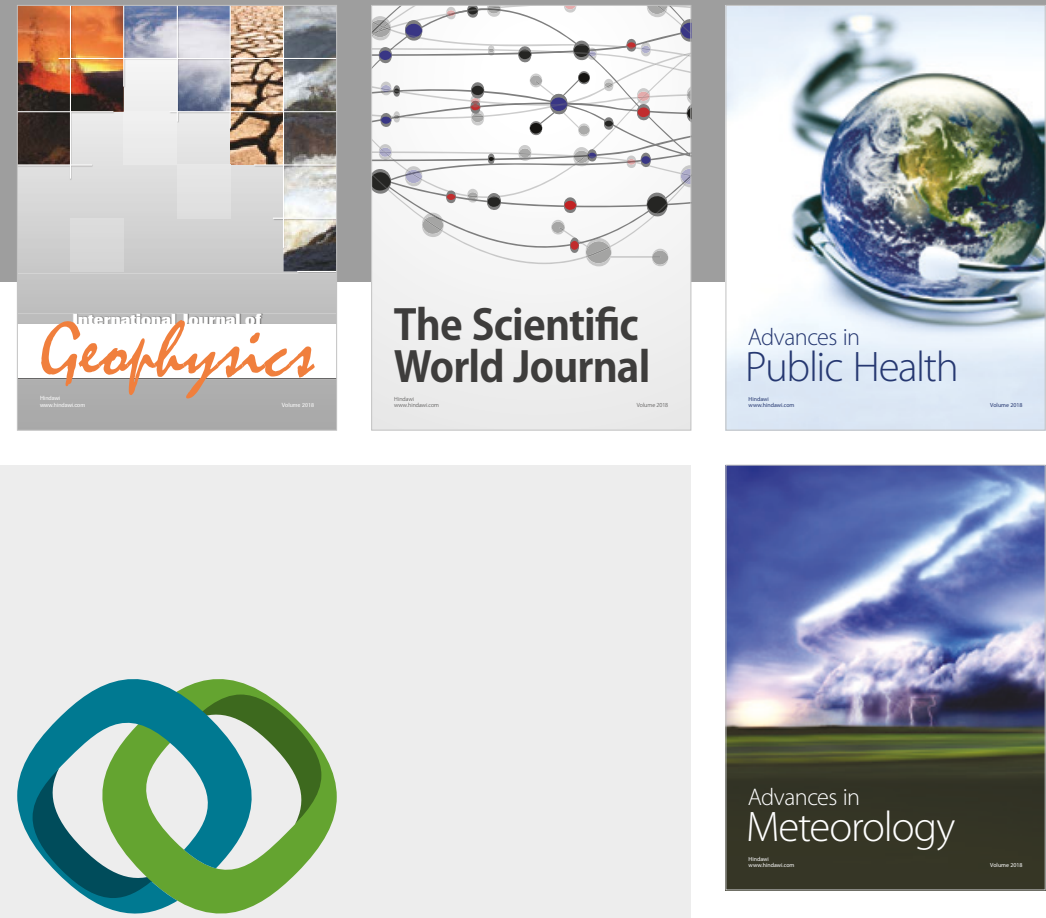

Advan

Public Health

\section{Hindawi}

Submit your manuscripts at

www.hindawi.com
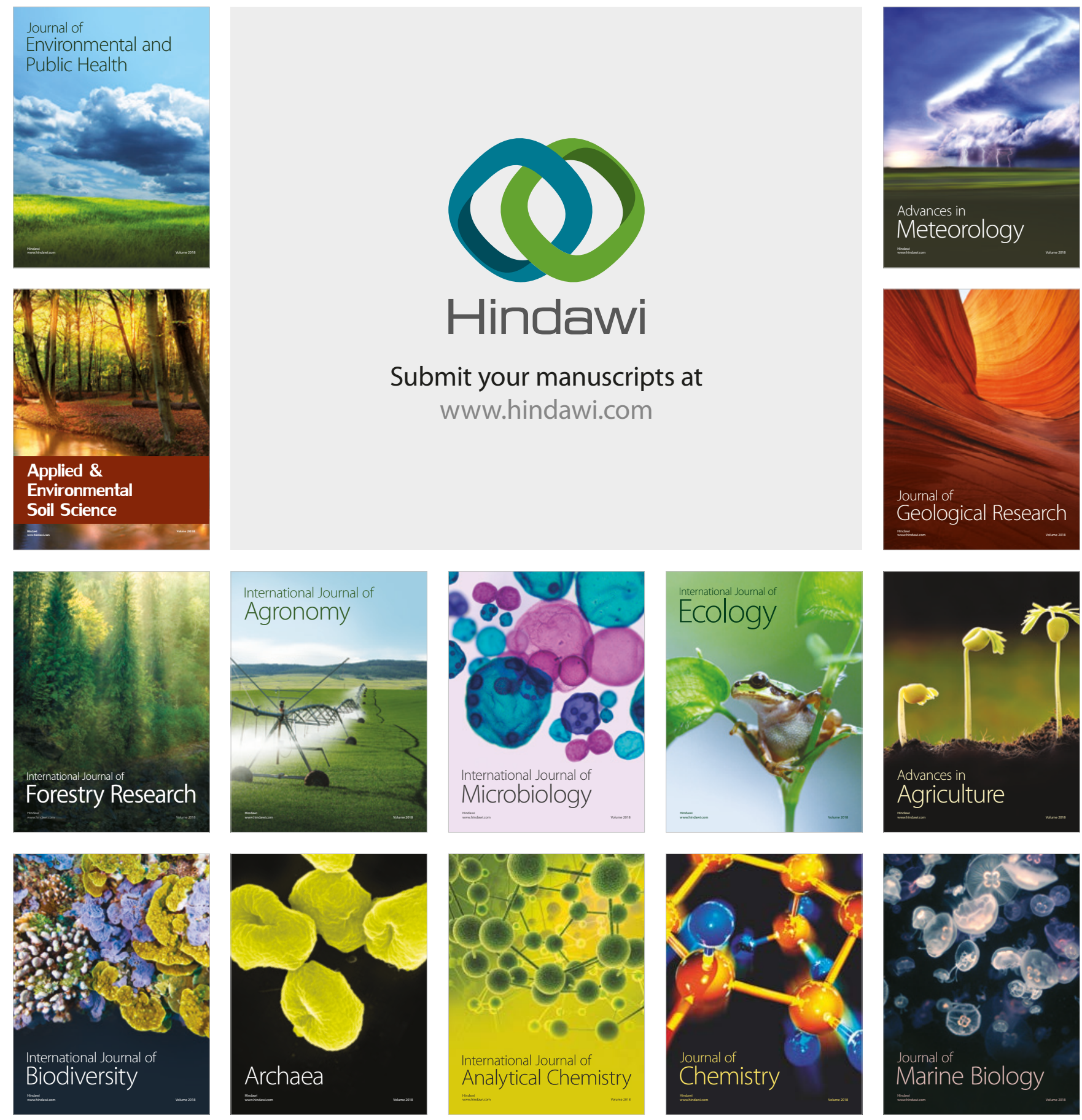